\title{
К концепции проекта Федерального закона «О Северном морском пути»
}

Гуреев С.A.*

Буник И.В.**

Северный морской путь - основная транспортная коммуникация в российском арктическом секторе, соединяющая Дальний Восток и западные районы страны и играющая ключевую роль в инфраструктуре экономического комплекса Крайнего Севера России в освоении природных ресурсов Северного Ледовитого океана'. Увеличение объема национальных и международных грузоперевозок по Северному морскому пути отвечает экономическим интересам нашей страны. Дальнейшее развитие судоходства и создание условий эффективного государственного управления арктическим сектором требуют развития и совершенствования нормативно-правовой базы, относяшейся к этому региону.

Относительно правового статуса российской Арктики высказываются разные точки зрения. Как отметил проф. А.Н. Вылегжанин, Арктика, согласно преобладающим взглядам в международно-правовой доктрине, - это часть земного шара, центром которой обозначен Северный географический полюс, а окраинной границей - Северный полярный круг (параллель 66 градусов 33 минуты северной широты). И далее: «Имеются разные оценки содержания международно-правового режима Арктики и даже понятий «Арктика», «Север», «Северный Ледовитый океан», «арктические государства». Например, Канада определила свою арктическую область как территорию, включаюшую прежде всего все земли севернее параллели 60 градусов северной широты, а также прибрежные районы заливов Гудзонова и Джеймса. К арктической области Дании отнесены острова Гренландия и Фарерские. Исландия включает в Арктику всю свою территорию. Законы

'Гуреев Сергей Александрович - Д.Ю.н., профессор.

“ Буник Иван Владимирович - юрист Центра правовых проблем СОПС при Президиуме РAH.

' О правовом режиме морских природных ресурсов см.: Вылегжанин А.Н. Морские природные ресурсы (международно-правовой режси). М., 2001. 
Норвегии не выделяют понятия «арктическая территория». Согласно Федеральному закону от 19 июня 1996 г. «Об основах государственного регулирования социально-экономического развития Севера Российской Федерации», «Север - высокоширотная часть территории Российской Федерации, характеризующаяся суровыми природно-климатическими условиями и повышенными затратами на производство продукции и жизнеобеспечение населения» (cr. 1)»².

Сторонники концепции полярных секторов, выступаюшие против интернационализации Арктики, обосновывают свои позиции ссылкой на известное Постановление Президиума Центрального Комитета СССР «Об объявлении территорией Союза ССР земель и островов, расположенных в Северном Ледовитом океане» от 15 апреля 1926 r., а также на опыт правового регулирования Канады в отношении ее арктического сектора. Так, в законодательстве России (царские указы 1616-1620 гг; Указ Сената 1821 г.; распоряжения российского императора 1833 и 1869 гг., Инструкция 1893 г. и др.) был предусмотрен ряд исключительных прав нашей страны в некоторых районах Арктики. В циркулярной депеше российского правительства от 20 сентября 1916 г. подтверждалось, что частью территории России являются острова, «расположенные вдоль азиатского побережья Империи» и составляющие «продолжение к северу» континентального пространства Сибири. Упомянутым выше Постановлением Президиума ЦИК СССР от 15 апреля 1926 г. территорией СССР были объявлены все, как открытые, так и могущие быть открытыми в дальнейшем земли и острова, не составляющие к моменту опубликования настоящего постановления признанной правительством Союза ССР территории каких-либо иностранных государств, расположенные в Северном Ледовитом океане к северу от побережья Союза ССР до Северного полюса в пределах между меридианом 32 градуса 04 минуты 35 секунд восточной долготы и меридианом 168 градусов 49 минут 30 секунд западной долготы ${ }^{3}$.

Другие авторы предлагают распространять на арктические моря России - Баренцево, Карское, Лаптевых, Восточно-Сибирское и Чукотское - тот же международно-правовой режим, что и на остальные районы Мирового океана. В связи с этим отмечается: «Сопоставитель-

'Вылегжанин А.Н., Гуреев С.А., Иванов Г.Г. Международное морское право. М., 2003. C. 214-217.

${ }^{3}$ Там же. С. 219. 
ный анализ применимых норм международного права... приводит к заключению, что международно-правовой режим арктического региона формируется на основе принципов и норм, имеющих общий характер для всего Мирового океана. В этом районе присутствуют все категории морских пространств, известных современному международному морскому праву: внутренние воды, территориальное море, прилежащая зона, экономические и рыболовные зоны, континентальный шельф, открытое море и участки морского дна, расположенные за пределами национальной юрисдикции ${ }^{4}$.

Не углубляясь в суть противоречий, отметим, что в целом концепция «полярных секторов» в большей мере отвечает национальным интересам России и вместе с тем не противоречит императивным нормам международного права.

Ряд обстоятельств затрудняет применение в полном объеме и без каких-либо ограничений к правовому режиму арктических морей России норм Конвенции ООН по морскому праву 1982 г. Во-первых, отличительной особенностью морей бассейна Северного Ледовитого океана является их относительно небольшая глубина, редко превышающая 200 метров, и то обстоятельство, что они большую часть года (до 9 месяцев) покрыты непроходимыми для обычных судов льдами. Определить в целях Конвенции ООН по морскому праву 1982 г, где заканчивается суша и начинается ледовая поверхность моря, практически невозможно. Во-вторых, существенной особенностью, определяющей режим российских арктических морей, является наличие проходящей через них трассы Северного морского пути - национальной единой транспортной коммуникации России в Арктике; попытка применить Конвенцию 1982 г. для определения порядка плавания судов по Северному морскому пути приводит к возникновению новых противоречий, так как прохождение трассы Севморпути меняется в зависимости от ледовой обстановки (см. прилагаемую схему): она проходит через внутренние морские воды России, ее территориальное море или в ее исключительной экономической зоне, а при отступлении льдов на север и в открытом море. То обстоятельство, что отдельные участки трасс в тот или иной период времени могут пролегать в открытом море, не оказывает влияния на целостность этой транспортной коммуникации, так как нахождение судна на таких участках невозможно без пред-

${ }^{4}$ Колодкин А.Л., Королева Н.Д., Марков В.Ю. Правовой режим российских арктических морей: некоторые аспекты // Ежегодник морского права. М., 1997. Ч. 1. С. 12 
варительного либо последующего пересечения российских вод (в том числе проливов, не являющихся международными с точки зрения Конвенции ООН по морскому праву 1982 г.) Существенными являются также обстоятельства исторического характера, связанные с вкладом российского и советского государств в изучение, освоение и оборудование Севморпути как транспортной магистрали (равно как и всей прилежащей к нему части Арктики, где располагаются принадлежащие России континентальные и островные территории).

Совокупность отмеченных факторов обусловила то, что сторонники разных подходов сходятся в отнесении Северного морского пути к категории национальных коммуникаций, что предполагает исключительные права России на регулирование порядка прохождения судов по этой трассе.

Отметим, что Арктику неправомерно приравнивать и к Антарктике, имеющей особый международно-правовой режим в соответствии с Договором 1959 г.

Конвенция ООН по морскому праву практически не закрепила правовой режим Арктики, имея в виду то, что вопросы использования арктических пространств достаточно эффективно регулируются на национальном уровне.

Анализ законодательной практики сопредельных с арктическим регионом стран (Канады, США, Дании, Норвегии), касающейся установления правового режима Арктики и регулирования всех видов деятельности в ее пределах, позволяет сделать вывод о том, что общий правовой режим региона, обособленного в географическом и политико-административном отношении, формировался так же, как и в России, под воздействием ряда факторов природного, исторического, экономического, демографического и военно-политического порядка. Особенности геополитического положения всех арктических государств, и Российской Федерации в частности, обусловили их заинтересованность в осуществлении надзора над всеми видами деятельности, проводимой в прилегающих арктических водах. Северный морской путь Российской Федерации, шхерный морской путь «Индрелея» Норвегии, Северо-западный проход Канады объединяет то, что все они являются историческими национальными морскими путями указанных государств (и не являются международными проливами), так как ведут к их историческим заливам и морям или находятся в стороне от путей международного судоходства. Приарктические государства стре- 
мятся усилить роль национального законодательства в общем правовом режиме прилегающих к их побережью районов Арктики. Эти районы являются зоной реализации исторически сложившихся оборонных, особых экономических, природоресурсных и природоохранных интересов соответствующих приарктических государств.

Итак, совершенствование правового регулирования судоходства по Севморпути - задача прежде всего национального законодательства Российской Федерации. Макроэкономические перспективы использования этого судоходного пути придают упомянутой задаче особую актуальность и значение, предполагающие разработку специального федерального закона, посвященного исключительно этому вопросу.

Международно-правовым основанием для разработки такого закона являются не только права арктических государств, исторически сложившиеся и давно осуществляемые, не только суверенитет России над внутренними морскими водами, но и права, предусмотренные в ст. 234 Конвенции по морскому праву 1982 г. ${ }^{5}$, которую Россия ратифицировала в 1997 г. ${ }^{6}$ Согласно положениям ст. 234 этой Конвенции, прибрежные государства имеют право принимать и обеспечивать соблюдение недискриминационных законов и правил по предотвращению, сокращению и сохранению под контролем загрязнения морской среды с судов в покрытых льдами районах в пределах исключительной экономической зоны, где особо суровые климатические условия и наличие льдов, покрывающих такие районы в течение большей части года, создают препятствия либо повышенную опасность для судоходства, а загрязнение морской среды могло бы нанести тяжелый вред экологическому равновесию. В развитие этой статьи в России должны быть приняты соответствующие нормативно-правовые акты.

Разработка проекта Федерального закона «О Северном морском пути Российской Федерации» была предусмотрена еще Планом законотворческой работы Правительства РФ на 2003 г. Совету по изучению производительных сил при Президиуме РАН было поручено в связи с этим разработать проект концепции и предварительный (рабочий) вариант законопроекта. Отправным пунктом законопроекта стали положения Федерального закона от 31 июля 1998 г. № 155-Ф3 «О внутренних мор-

\footnotetext{
${ }_{5}^{5}$ Конвенция Организации Объединенных Наций по морскому праву (Монтего-Бей, 10 декабря 1982 г.) // С3 РФ от 1 декабря 1997 г., № 48, ст. 5493.

${ }^{6}$ Федеральный закон от 26 февраля 1997 г. № 30-Ф3 «О ратификации Конвенции Организашии Объединенных Наций по морскому праву и Соглашения об осуществлении части XI Конвенции Организации Объединенных Наций по морскому праву" // СЗ РФ от 3 марта 1997 г., № 9, ст. 1013.
} 
ских водах, территориальном море и прилежашей зоне Российской Фе-

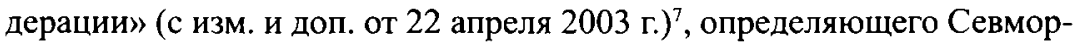
путь как исторически сложившуюся национальную единую транспортную коммуникацию Российской Федерации в Арктике. В Законе указывается, во-первых, на исторические основания для признания Северного морского пути национальной коммуникацией России в Арктике. Во-вторых, - на ее национальный характер как российского внутреннего водного пути. И в-третьих, на единство, т.е. его нерасчлененность на какие-либо отдельные участки, что подчеркивает федеральный характер Северного морского пути.

До 1991 г. Севморпуть не использовался для прохода иностранных судов. В настоящее время плавание по его трассам осуществляется в соответствии с указанным федеральным законом и «Правилами плавания по Северному морскому пути», вступившими в силу 1 июля 1991 г., а также международными договорами Российской Федерации.

В ходе работы над концепцией и законопроектом был исследован: 1) предыдущий отечественный нормотворческий опыт в данной области; 2) современный международно-правовой статус Арктики и тенденции его развития; 3) иностранный опыт законодательного регулирования экономической деятельности в Арктике.

Законопроект направлен на реализацию Морской доктрины Российской Федерации на период до 2020 года, утвержденной Президентом Российской Федерации (№ Пр-1387) 27 июля 2001 г., согласно положениям которой национальная морская политика на арктическом региональном направлении определяется помимо прочего и возрастающим значением Северного морского пути для устойчивого развития Российской Федерации. При этом в Морской доктрине применительно к Северному морскому пути отдельно обозначено решение таких долгосрочных задач, как обеспечение национальных интересов Российской Федерации в отношении Северного морского пути, централизованное государственное управление этой транспортной системой, ледокольное обслуживание и предоставление равноправного доступа заинтересованным перевозчикам, в том числе иностранным. Кроме этого разрабатываемый проект федерального закона будет иметь важное значение во внутреннем законодательстве России как правовой акт, направленный на реализацию ст. 234 (Покрытые льдом районы) Конвенции ООН по морскому праву 1982 г.

${ }^{7}$ C3 РФ or 3 августа 1998 г., № 31, ст. 3833. 
Основной целью проекта является подтверждение и уточнение статуса и правового режима Северного морского пути, а также связанных с эксплуатацией Северного морского пути мер по предотвращению, сокращению и сохранению под контролем загрязнения морской среды с судов в покрытых льдами районах в связи с повышенной опасностью для судоходства и угрозой экологическому равновесию от загрязнения морской среды. Законопроект составлен с учетом международного опыта разработки правовых норм и стандартов в данной облас$\mathbf{T и}^{8}$, а также национального опыта других приарктических государств - США, Норвегии, и особенно Канады, раньше России проявившей заинтересованность в определении статуса Северо-западного прохода. Этот опыт представляет большой интерес и для нашей страны. Правовые проблемы использования Северо-западного прохода Канады обсуждаются уже давно. Так, еще в 1980 г. Д. Фаранд, ведущий канадский специалист по этой проблеме, высказал мнение, что Канаде следовало бы официально ограничить зоны свободного плавания иностранных судов вблизи островов Канадского Арктического архипелага, объявив эти акватории внутренними водами, и проработать другие новые меры и акты правового характера'. Позднее, в другом своем исследовании, Д. Фаранд не исключал возможности в будущем, при развитии международного судоходства по Северо-западному проходу, применения к судоходству по нему права свободного прохода вместе с принятием соответствуюших превентивных мер по охране своих вод от загрязнения и осуществлением контроля за плаванием иностранных судов. Он подчеркнул, что интернационализация Северо-западного прохода негативно повлияет не только на состояние водной среды Арктики, но и на благополучие местного населения и безопасность Канады. Вот почему, по мнению Д. Фаранда, Канаде надлежит развивать свои собственные средства наблюдения и обороны в Арктике ${ }^{10}$.

Разрабатываемый закон «О Северном морском пути» после его принятия может органично вписаться в «морское» законодательство России, включающее, в частности, Федеральные законы «О внутренних морских водах, территориальном море и прилежащей зоне Российс-

\footnotetext{
${ }^{8}$ Напр., Доклад ИМО по Проекту правил плавания судов в покрытых льдами арктических водах // IMO DE 45/27/Add.2 1 July 2002.

${ }^{9}$ North-Nord, 1980, 27, № 3, P. $2-7$.

${ }^{10}$ Pharand D. and Legault, L.H. International straits of the world. The Northwest Passage: Arctic straits. Dordrecht: Martinus Nijhoff, 1984. См. также: Pharand, D. Canada's Waters in International Law: Cambridge: University Press, 1988.
} 
кой Федерации» от 31 июля 1998 г. № 155 - Ф3, «Об исключительной экономической зоне Российской Федерации» от 17 декабря 1998 г. № 191-Ф3", «О континентальном шельфе Российской Федерации» от 30 ноября 1995 г. № 187-Ф3'2, и занять надлежащее место в системе других федеральных законов, в том числе «Об охране окружающей среды» от 10 января 2002 г. № 7-Ф3 ${ }^{13}$ и «О Государственной границе Российской Федерации» от 1 апреля 1993 г. № 4730-I'14.

Действие закона предполагается распространить на невоенные суда, допущенные на трассы Северного морского пути, плавающие под Государственным флагом Российской Федерации, и суда, плавающие под флагами иностранных государств, заходящие в порты, открытые для международного судоходства, а также на российские и иностранные военный корабли. При этом в законопроекте проводится различие между режимами прохода по Северному морскому пути, с одной стороны, иностранных невоенных судов, а с другой - иностранных военных кораблей, военно-вспомогательных судов и государственных судов, находящихся на правительственной службе. Если первые, согласно законопроекту, осуществляют проход на основе подачи уведомления и заявки в Администрацию и ее информации о возможности проводки (прохода), то суда второй группы допускаются на трассы Северного морского пути только по специальному разрешению, получаемому в дипломатическом порядке. Основанием для такого разделения является то, что Северный морской путь является исторически сложившейся национальной российской транспортной коммуникацией в Арктике, на которой в целом действует режим внутренних морских вод России.

Выдвигаемые США идеи интернационализации Арктики вообще и Северного морского пути (как и Северо-западного прохода) в частности не получили поддержки в актах национального и международного права. Как уже отмечалось, Конвенция ООН по морскому праву 1982 г. практически не затрагивает правового режима Арктики. В настоящее время международное сотрудничество государств по вопросам защиты окружающей среды Арктики и ее устойчивого развития ограничено рамками деятельности Арктического Совета, созданного

"С3 РФ от 21 декабря 1998 г., № 51, ст. 6273.

12 С 3 РФ от 4 декабря 1995 г., № 49, ст. 4694.

${ }^{13}$ С3 РФ от 14 января 2002 г., № 2, ст. 133.

${ }^{14}$ Ведомости Съезда народных депутатов Российской Федерации и Верховного Совета Российской Федерации от 29 апреля 1993 г., № 17, ст. 594. 
в качестве «форума», а не международной организации. Выбор такой организационной структуры соответствует современной практике неформального межгосударственного сотрудничества (например, ОБСЕ) и оказывает существенное влияние на то, как Совет выполняет свои функции.

В Арктическом Совете как неформальной организации возможно обсуждение важных и противоречивых вопросов, однако решение принимается на основе консенсуса. Поэтому решения устраивают всех участников и выполняются всеми организациями. Следовательно, нет необходимости в разработке правовых норм об ответственности за неисполнение и о процедурах разрешения споров. Решения в Совете и его вспомогательных органах принимаются всеми восьмью арктическими странами на основе консенсуса ${ }^{15}$. Всякая деятельность вообще и нововведения в частности возможны только после одобрения министров арктических стран на двухлетней встрече. Старшие должностные лица по Арктике (англ. senior arctic officials), руководящие работой Совета, лишь подготавливают предложения для передачи их на утверждение министров. Таким образом, Совет представляет из себя скорее форум для обмена мнениями, а не оперативный орган, способный, например, действовать в чрезвычайных ситуациях. Следовательно, Арктический Совет не ограничивает компетенцию арктических государств, в том числе в отношении действий в чрезвычайных ситуация ${ }^{16}$. Государства по отдельности или коллективно могут действовать независимо от Совета.

Вышеизложенное позволяет еще раз сделать вывод: в международном праве признается, что вопросы использования арктических пространств достаточно эффективно регулируются на национальном уровне.

Положения проекта Федерального закона «О Северном морском пути» направлены на восполнение пробелов в российском законодательстве при сохранении юридической силы ряда действующих нормативных актов и уточнении их редакции.

В проекте закона о Северном морском пути подтверждается статус Северного морского пути как исторически сложившейся национальной российской транспортной коммуникации в Арктике и устанавливаются его границы в соответствии с Конституцией Российской Феде-

${ }^{15}$ Declaration on the Establishment of the Arctic Council, 35 ILM 1387 (1996), а также Arctic Council Rules of Procedure, Rule 7.

${ }^{16}$ Подробнее см.: Bloom E. Establishment of the Arctic Council // 93 AJIL 712 (1999). 
рации. Федеральными законами “О внутренних морских водах, территориальном море и прилежащей зоне) (с измснениями от 22 апреля, 30 июня. 11 ноября 2003 г.) и «Об иск-1ючительной экономической зоне Российской Федерации" от 17 декао̄ря 1998 г. Кроме этого, важно в русле исполнения треб́ований Морской доктрины уточнить цели государственного управления и статус Администрации Северного морского пути. В этой связи целесообразно разработать Положение об этом органе как самостоятельной структуре в аппарате Правительства России или как подразделении Министерства транспорта РФ.

В национальных интересах России определить именно в федеральном законодательном акте основные требования к доступу судов на трассы Северного морского пути и особенности их плавания, поскольку именно федеральный закон может устанавливать жесткие нормы уровня загрязнсния морской среды с судов в покрытых льдами районах в связи с повышенной опасностью для судоходства и угрозой экологическому равновесию, а также требоования к судам и экипажам судов. В связи с этим в законопроекте учтены требования по защите морской среды от загрязнения, содержашиеся в Конвенции ООН по морскому праву 1982 г., согласно которым (статын 211, 234 и 235) прибрежное государство принимает законы и правила для предотвращения и сохранения под контролем загрязнения морской среды. Законопроект должен дсйствовать с учетом положений и других международных договоров. заключснных Российской Федерацией: по предотвращению загрязнения с судов, со́роса отходов и других материалов, а также Международной конвенции 1996 г. оо̄ ответственности и компенсации ущерб́а в связи с перевозкой морем опасных и вредных веществ ${ }^{17}$ в части необходимости наличия свндетельств о финансовом обеспечении гражданской ответственности владельца судна за ущерб от загрязнения морской среды. Задача защиты и сохранения хрупкого экологического баланса Арктики является общей и актуальной для всех приарктических государств. В арктических условиях эта проблема приобретает особое значение, так как сброс загрязняющих веществ судами при следовании по трассам Северного морского пути либо захоронение отходов и материалов (равно как и промышленное освоение минеральных ресурсов, их транспортировка танкерами или по тру-

${ }^{17}$ Intemational Convention on Liability and Compensation for Damage in connection with the Carriage ol Hazardous and Noxious Substances by Sea. Jloндон, 3 мая 1996 r. Не вслу-

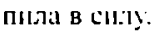


бопроводам) чреваты возможным серьезным загрязнением окружающсй срсды, которос может нанссти непоправимый ущсрб флоре и фауне Арктики (особо уязвимым вследствие ряда факторов: низкого радиационного баланса, близких к нулю средних температур летних месяцев при отрицательной среднегодовой температуре, существования лсдников и вечной мерзлоты, преобладания тундровой растительности и арктических пустынь, а также значительной площади покрытых льдом акваторий). Многочисленные научные исследования доказывают факты загрязнения арктической пищевой цепи (приводящего к необратимым изменениям в экосистемах) вследствие деятельности чело-

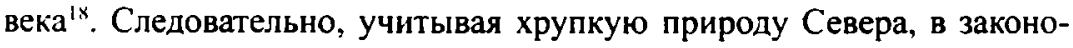
проекте запрешен выб́рос загрязняюших веществ судами при следовании по трассам Северного морского пути и захоронение отходов и материалов.

При разработке правовых способов решения вопросов, связанных с проблемами защиты морской среды Арктики, авторы российского законопроекта в особенности учли положения канадского Закона о предотврашении загрязнения арктических вод 1970 г. (англ. Arctic Waters Pollution Prevention Act 1970) 19 . Однако (с учетом действующего российского законодательства) полномочия Администрации Северного морского пути и ее должностных лиц - по сравнению с зарубежным законодательством - значительно уже, чем в подобных организациях других приарктических стран, в т.ч. Канады. Так, канадским Законом 1970 г. установлены широкие права по контролю за загрязнением в районах на расстоянии 100 миль от любой точки канадского берега к северу от $60^{\circ}$ северной широты. В пределах этого района правительство получает возможность осушествления эффективного международного контроля над проходом судов. Отметим, что вслед за принятием Закона 1970 г. последовали ожесточенные дебаты противников и сторонников факта стремления Канады распространить суверенитет на ее арктический сектор, в особенности со

"С... напр.: Яблоков В.К., Карасев В.М. и др. Факты и ироблемы, связанные с захоронснием радиоактивных отходов в морях, омывающих территорию Российской Феxepausut. M., 1993; Stephanie Pfinman, Kathleen Crane, and Peter deFur. Arctic Contaminant Distribution // CARC - Northern Perspectives (Volume 21. Number 4, Winter 1993-94); Johunnessen, O. M.. E. V. Shalina and M. W. Miles. Satellite evidence for and Aretic sea ice coverage in transformation. // Science., 286, 1937-1939, 1999.

" 9 INT. LEGAL MATERIALS 543 (1970). Коммснтариї к Закону см.: Wilkes. International Due Process and Control of Pollution - The Cancedian Arctic Waters Example. 2. . MAR. L. \& COMM. 499(1971). 
стороны США ${ }^{20}$. До принятия Закона 1970 г. на воды канадской Арктики распространялся принцип свободы открытого моря. То, что действия Канады не противоречат нормам международного права, было основательно доказано в статье американского юриста-международника Дж. К. Клотца ${ }^{21}$. Во-первых, Д. Клотц отмечает, что Канада заявляла не о суверенитете над арктическими водами, а лишь о праве осуществлять специальную юрисдикцию в целях предотвращения загрязнения. Вовторых, эта специальная юрисдикция во многом правомерна с точки зрения пяти общепризнанных оснований для осуществления национальной юрисдикции (принципа территории; принципа защиты собственных интересов при наличии угрозы государственной безопасности; принципов осуществления юрисдикции в отношении собственных граждан, вне зависимости от их местонахождения или в отношении иностранцев, совершивших преступление против собственных граждан; принципа универсальности, т.е. защиты универсальных интересов: борьбы с пиратством, рабством и т.п.) $)^{22}$.

Правительство Канады не раз подчеркивало, что факт распространения юрисдикции основан не на одних лишь национальных интересах, а на действиях в интересах всего человечества при отсутствии эффективных норм международного права. Так, канадский премьерминистр Трюдо в свое время сделал следующее заявление: «...в условиях, когда не существует права или правовое регулирование явно неэффективно и нет общей международно-правовой нормы касательно арктических морей, мы утверждаем, что кто-то обязан сохранить этот район в интересах всего человечества, - не дожидаясь дальнейшего развития международного права» (англ. “.... where no law exists, or where law is clearly insufficient, there is no international common law applying to the Arctic Seas, we"re saying somebody has to preserve this area for mankind until international law develops"') ${ }^{23}$.

${ }^{20}$ Cм., напр.: Department of State Release. April 15, 1970. 64 AM. J. INT'L. L. 928 (1970); Terrance Wills. U.S. won't accept Canadian claims over Arctic waters // The Globe and Mail, April 101970.

21 JOHN C. KLOTZ. Are Ocean Polluters Subject to Universal Jurisdiction - Canada Breaks the Ice // The International Lawyer, Vol. 6, № 4, October 1972 P. 706

${ }^{22}$ См. Taкже: George F. Extraterritorial Application of Penal Legislation // 64 Michigan L.R. 609 (1966); Cowles D. University of Jurisdiction Over War Crimes // 33 CALIF. L. REV. 177 (1945); Carnegie, Jurisdiction Over Violations of the Laws and Customs of War / / 39 BRIT. Y.B. INT'L.L. 402 (1963).

${ }^{23}$ Press conference of Prime Minister Trudeau. April 8, 1970//9 INT. LEGAL MATERIALS 601 (1970). 
Еще раз отметим, что канадское законодательство во многом обосновано нормами международного права. Например, Международная конвенция относительно вмешательства в открытом море в случаях аварий, приводящих к загрязнению нефтью (Брюссель, 29 ноября 1969 г.) $)^{24}$ (статья 1) уполномочивает участвующие государства «принимать в открытом море такие меры, которые могут оказаться необходимыми для предотвращения, уменышения или устранения серьезной и реально угрожающей их побережью или связанным с ним интересам опасности загрязнения или угрозы загрязнения моря нефтью вследствие морской аварии или действий, связанных с такой аварией, которые, как разумно можно предполагать, повлекут за собой вредные последствия в больших размерах» (исключая такие меры в отношении какого-либо военного корабля или иного судна, принадлежашего Государству или эксплуатируемого им и используемого в данное время для правительственных некоммерческих целей).

В контексте анализа канадского законодательства с точки зрения норм международного права интересно обратиться к решению Постоянной палаты международного правосудия по делу судна «Лотос» в 1927 г. $^{25}$ При рассмотрении вопроса о легитимности турецкого законодательства (предполагающего осуществление юрисдикции за пределами государственной территории), ППМП установила: осучествление национальной юрисдикчии всегда легитимно, если отсутствует явный запрет со стороны нори международного права. Выше уже указывалось на возможность существования допустимых исключений из принципа свободы открытого моря (для защиты законных национальных интересов).

К сожалению, положительный опыт Канады невозможно в полной мере использовать при разработке российского законопроекта, поскольку в рамках правовой системы нашей страны Администрация Северного морского пути не может действовать так же оперативно и действенно и во многих случаях должна обращаться за помощью к другим государственным органам (прокуратуре, суду, органам Минприроды и др.).

\footnotetext{
${ }^{24}$ Вступила в силу 6.05.75 // Материалы по морскому праву и международному торговому мореплаванию. М.: «Транспорт». № 4. 1973. См. также: Протокол о вмешательстве в открытом море в случаях аварий, приводящих к загрязнению веществами, иными, чем нефть от 2.11.73 // Материалы по морскому праву и международному торговому мореплаванию. М.: «Транспорт». № 7.1975.

${ }^{25}$ P.C.I.J., Series A., № 10 (1927).
} 
В то же время в законопроекте закреплены, с учетом требований интересов защиты окружающей среды и предписаний зарубежного законодательства, важные положения.

Так, согласно законопроекту, капитан судна обязан оказывать инспектору по охране окружающей среды Администрации необходимое содействие для наиболее полного и быстрого осуществления контрольных осмотров. В случае причинения судами ущерба окружающей среде и (или) создания угрозы безопасности мореплавания, Администрация СМП на основании мотивированного представления инспектора вправе принимать решение о выводе судна с трассы и его направлении в определенное место, где оно должно находиться впредь до вынесения Администрацией решения о дальнейших действиях. Дополнительно к действующим обязательным требованиям о передаче сообщения о загрязнении морской среды капитан судна, следующего по Северному морскому пути, обязан незамедлительно информировать представителя Администрации о любом факте сброса загрязняющих веществ, совершенного данным судном или обнаруженного им. В законопроекте предлагается однозначно закрепить за Администрацией Северного морского пути право на рассмотрение дел об административных правонарушениях, связанных с загрязнением и засорением вод на трассах Северного морского пути и смежных с ним районов (по примеру ранее действовавшей статьи 219 Кодекса РСФСР об административных правонарушениях от 20 июня 1984 г. «Органы охраны водных ресурсов» и в соответствии с действующей в настоящее время статьей 22.1 Кодекса Российской Федерации об административных правонарушениях от 30 декабря 2001 г.).

Если имеются явные объективные доказательства того, что судно, проходящее по трассам Северного морского пути, совершило путем сброса загрязняющих веществ нарушение законов и правил России по предотвращению, сокращению и сохранению под контролем загрязнения морской среды и это нарушение привело к тяжкому ущербу или угрозе тяжкого ущерба арктическому сектору России, побережью или связанным с ним ее интересам, то Администрация Северного морского пути имеет право направить в Прокуратуру России соответствующие документы для решения вопроса об уголовном преследовании лиц, совершивших нарушение законодательства РФ об охране окружающей среды (т.е., как правило, судовладельцев). 
В соответствии с мировым опытом в законопроекте закреплена платность предоставления услуг на трассах Северного морского пути, исходя из затрат на содержание и эксплуатацию ледокольного флота, стоимости необходимой навигационной, гидрометеорологической и ледовой информации, прогнозов и рекомендаций для безопасного плавания, передаваемых капитанам судов и т.п.

Касаясь социально-экономических, политических, юридических и иных последствий реализации данного закона, следует отметить, что его принятие позволит обеспечить национальные интересы Российской Федерации в отношении Северного морского пути: увеличение экономической выгоды за счет платежей, взимаемых за услуги, предоставляемые судам (в том числе судам заинтересованных иностранных перевозчиков) при плавании по трассам, а также укрепление национальной безопасности Российской Федерации. Принятие законопроекта позволит обеспечить централизованное государственное управление этой транспортной системой, надлежащее ледокольное обслуживание и предоставит равноправный доступ заинтересованным перевозчикам, в том числе иностранным, а также окажет подлержку коренным малочисленным народам Севера.

Принятие законопроекта и реализация закона послужат созданию оптимальных условий для эффективного функционирования морского транспорта путем совершенствования правового регулирования отношений, возникающих из торгового мореплавания на трассах Северного морского пути.

Выводы.

1. Прежде всего, Арктику неправомерно приравнивать к Антарктике, имеющей особый международно-правовой режим в соответствии с Договором 1959 г. Конвенция ООН по морскому праву практически не закрепила правовой режим Арктики, имея в виду то, что вопросы использования арктических пространств достаточно эффективно регулируются на национальном уровне. Это подтверждает и сравнительное изучение национального законодательства приарктических государств.

2. В проекте Федерального закона «О Северном морском пути», разработанном на основе изучения отечественного и зарубежного законодательства, предлагается подтвердить существующий уведомительно-разрешительный порядок допуска невоенных судов на трассы Северного морского пути и установить разрешительный порядок про- 
хода военных кораблей, военно-вспомогательных судов и иных иностранных судов, эксплуатируемых и используемых в данное время для правительственных некоммерческих целей.

3. Предлагается определить связанные с эксплуатацией Северного морского пути необходимые меры по предотвращению, сокращению и сохранению под контролем загрязнений морской среды с судов в покрытых льдами районах, а также ужесточить ответственность судовладельцев и государства флага за такие загрязнения.

4. В то же время международное сотрудничество в Арктике (в том числе в рамках встреч Арктического Совета) целесообразно развивать и совершенствовать по некоторым вопросам, представляющим общий интерес, в первую очередь - связанным с охраной окружающей среды и устойчивым развитием. 


\section{ПРИЛОЖЕНИЕ 1.}

\section{Схема 1. Изменение курсов Северного морского пути'}
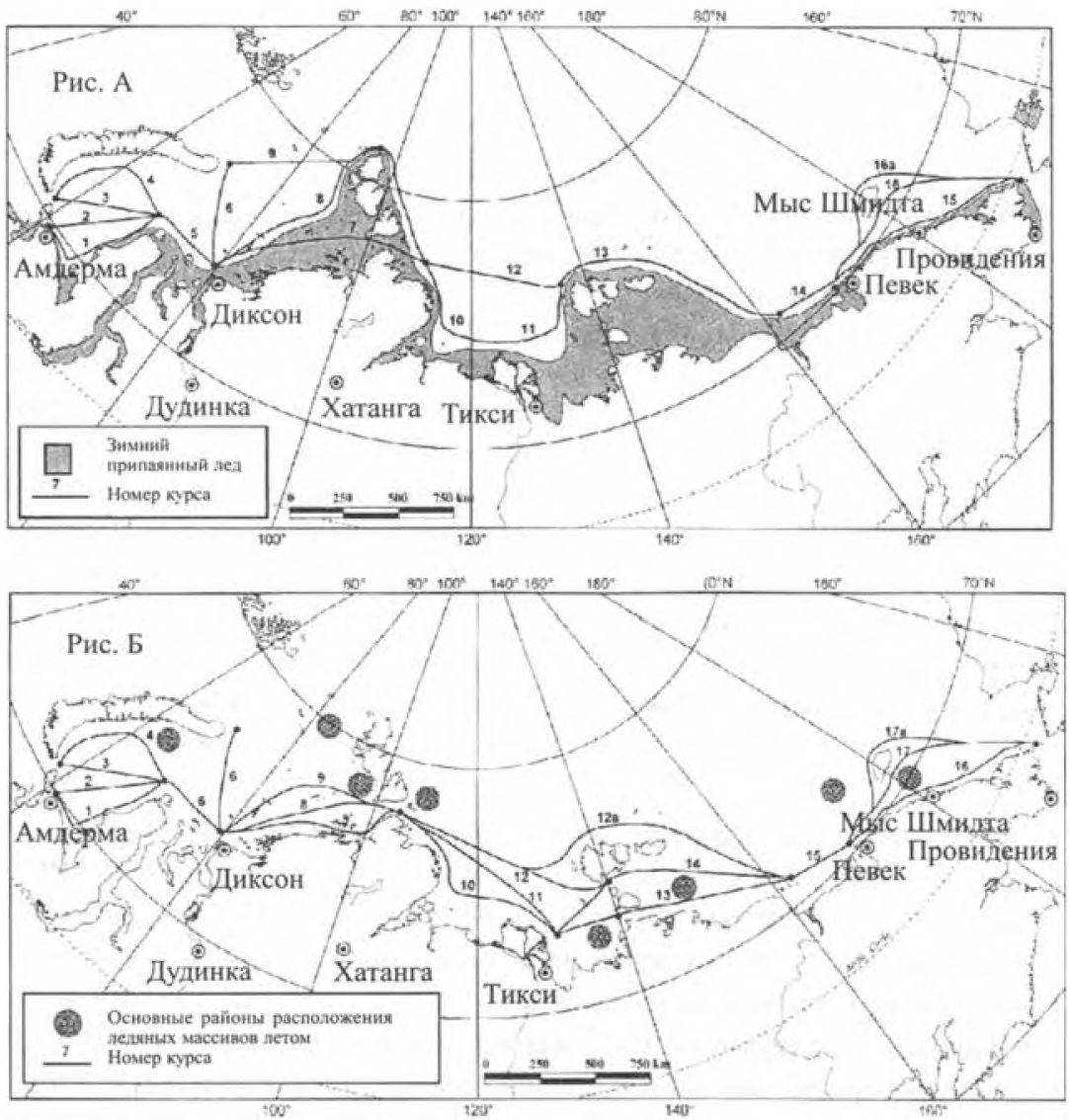

Рис. A - основные курсы Севморпути, рекомендованные для исполњзования с ноября по май.

Рис. Б - основные курсы, реномендованные для использования с июня по октябрь-

' Модифищированньй вариант карты, представленной в NSPOR Woking Poper no. 108-1998. 